\title{
Neologi Istilah Politik Dalam Bahasa Arab Modern Kajian Morfologi
}

\author{
Nurul Aini \\ Universitas Gadjah Mada \\ Aininurrahman@gmail.com
}

\begin{abstract}
This study aims to determine the forms and rules of formation of political terms in Arabic language examined from the morphological aspects. This type of research is literature research. Data collection using direct observation method. Data analysis using top down method of distribution technique and data presentation using informal method. The results of this study show the form of political terms in Arabic consists of the form of words and phrases. The word form consists of nouns and verbs, either in the basic form of the word or affixation. The form of phrase consists of tarkib idhafi, verbal phrases, nominal phrases, jarr majrur and tarkib wasfi. The rule formation of Arabic political terms viewed from the morphological aspect consists of: a) the derivation of masdar, isim fá'il, isim maf'ul, isim makān b) absorption, c) translation.
\end{abstract}

Keywords: neology, political term, morphology

\begin{abstract}
Abstrak
Penelitian ini bertujuan untuk mengetahui bentuk-bentuk dan kaidah pembentukan istilah politik dalam bahasa Arab dikaji dari aspek morfologi. Jenis penelitian ini adalah penelitian pustaka. Pengumpulan data menggunakan metode observasi langsung terhadap sumber-sumber kepustakaan. Analisis data menggunakan metode distribusional teknik top downdanpenyajian data menggunakan metode informal. Adapun hasil dari penelitian ini menunjukkan bentuk istilah politik dalam bahasa Arab terdiri dari bentuk kata dan frasa. Bentuk kata terdiri dari nomina dan verba, baik berupa kata dasar maupun berafiks. Adapun bentuk frasa terdiri dari tarkib idhafi, frasa verbal, frasanominal, jarr majrur dan tarkib wasfi. Kaidah pembentukan istilah politik bahasa Arab ditinjau dari aspek morfologis terdiri dari: a) derivasi berupa masdar, isim fálil, isim maf ül, isim makān, b) penyerapan, c) penerjemahan.
\end{abstract}

Kata kunci: neologi, istilah politik, morfologi

Arabiyatuna : Jurnal Bahasa Arab, Vol. 2, No. 2, 2018

P-ISSN: 2580-5045; E-ISSN: 2580-5053

Available online: http://journal.staincurup.ac.id/index.php/arabiyatuna 


\section{Pendahuluan}

Bahasa merupakan produk kreativitas manusia yang tidak lepas dari segala aktivitas manusia. Segala gerak dan tindakan manusia menggunakan bahasa. Bahasa bersifat dinamis artinya bahasa berubah dan berkembang seiring dengan perubahan dan perkembangan masyarakat ${ }^{1}$. Kedinamisan bahasa berkembang sesuai dengan perkembangan manusia. Perubahan zaman, perkembangan ilmu pengetahuan dan teknologi, akulturasi budaya serta globalisasi yang semakin luas mempengaruhi perubahan bahasa di masyarakat. Tidak ada satu bahasa pun yang sudah memiliki kosakata yang lengkap dan tidak memerlukan ungkapan untuk gagasan, temuan, atau rekaciptanya yang baru$^{2}$. Begitu pula yang terjadi di dalam bahasa Arab. Bahasa Arab adalah salah satu dari 3500 bahasa yang ada di dunia. Bahasa yang merupakan turunan dari bahasa Semit dan masih digunakan sampai saat ini ${ }^{3}$ serta telah diakui sebagai bahasa Internasional oleh UNESCO pada tahun $1973^{4}$.

Akibat adanya globalisasi, bahasa Arab telah mendapat pengaruh dari budaya dan masyarakat lainnya melalui kontak bahasa. Sebagai hasil dari kontak ini, bahasa Arab telah meminjam banyak kata, gagasan, dan konsep dari bahasa lain. Akademisi Arab di Kairo, Damaskus, Baghdad dan Amman telah aktif dalam standarisasi bahasa Arab, pengenalan istilah dan konsep baru ke dalam bahasa Arab ${ }^{5}$. Hal ini dilakukan agar bahasa Arab terus terjaga meskipun telah banyak terpengaruh oleh bahasa asing yang masuk dalam peristilahanperistilahan baru di dalam bahasa Arab.

Salah satu perubahan yang paling menonjol diakibatkan oleh adanya globalisasi. Menurut Waters, globalisasi adalah sebuah proses sosial yang membawa akibat bahwa pembatasan geografis pada keadaan sosial, budaya, ideologi dan politik menjadi kurang penting. Hal yang lebih penting adalah menjelmakan di dalam kesadaran orang untuk hidup dalam satu aturan yang mendunia ${ }^{6}$.

Perubahan sosial, perkembangan masyarakat serta derasnya arus globalisasi inilah yang menyebabkan perubahan pada bahasa pula. Adanya komunikasi global menyebabkanbanyak istilah-istilah baru yang antara satu

1 Abdul Chaer, Linguistik Umum, (Jakarta: Rineka Cipta, 2012), hlm. 53

${ }^{2}$ Ernawati Waridah, EYD: Ejaan Yang Disempurnakan dan Seputar KebahasaIndonesiaan, (Bandung: Ruang Kata, 2012), hlm. 66

${ }^{3}$ Aziz Anwar Fachrudin, Pengantar Sejarah dan Mazhab Linguistik Arab, (Sidoarjo: CV. Lisan Arabi, 2017), hlm. 17

${ }^{4}$ M.H. Bakalla, Arabic Culture Through its Language and Literature, (London: Kegan Paul International, 1984), hlm. 7

5 Ibid, hlm. 11

${ }^{6}$ Mohammad Shoelhi, Komunikasi Lintas Budaya dalam Dinamika Komunikasi Internasional, (Bandung: Simbiosa Rekatama Media, 2015), hlm. 158 
bahasa dengan yang lainnya membutuhkan penyesuaian. Sehingga bahasa berkembang menciptakan istilah baru dan makna barubaik dalam bidang ekonomi, sosial, politik, teknologi dan lain sebagainya. Banyak istilah-istilah baru yang muncul sebagai dampak adanya perubahan sosial dari masyarakat. Istilah baru dalam bahasa muncul karena tidak tersedianya istilah tersebut dalam bahasa mereka sendiri, sedangkan kebutuhan istilah tersebut untuk berkomunikasi sangat dibutuhkan. Oleh karen itu pembentukan istilah merupakan suatu keniscayaan dalam suatu bahasa. Pembentukan istilah bisa dilakukan dengan cara meminjam istilah yang sudah ada dari bahasa asing dan menerjemahkan ke dalam bahasanya ataupun menggunakan istilah lama dengan makna yang baru baik diperluas maupun dipersempit. Hal ini pula yang terjadi dalam bahasa Arab.

Salah satu bidang yang berkembang di zaman ini adalah bidang politik. Di dalam kamus Arabic-English Thematic lexicon karya Daniel Newman misalnya, ada berbagai istilah politik di dalam bahasa Arab yang diambil dari bahasa Inggris antara lain برلمان (Parlemen), برتوكول (Protocol), اعتلافات (Caalition), تشريعي (Legislative), الكتروني تصويت (electronic voting), الليبرالي الديموقراطي الحزب (Liberal Democratic Party (UK)) dan berbagai istilah lainnya.

Istilah-istilah tersebut merupakan sebagian contoh adanya istilah baru yang digunakan pada era saat ini. Hal itu bertujuan agar bahasa Arab dapat menyesuaikan dengan perkembangan zaman. Selain itu, penelitian ini diharapkan dapat memberikan kontribusi penting dalam mempelajari ilmu bahasa Arab khususnya dalam bidang pembentukan istilah politik serta memberikan pengetahuan tentang istilah-istilah politik dalam bahasa Arab modern.

Dari berbagai permasalahan di atas maka dapat dirumuskan rumusan masalah antara lain: 1) bagaimana bentuk istilah-istilah bahasa Arab modern dalam bidang politik dan 2) bagaimana kaidah pembentukan istilah-istilah tersebut. Adapun fokus penelitian ini dibatasi hanya dari aspek morfologi.

Penelitian ini merupakan jenis penelitian pustaka (library research) dilakukan dengan mengkaji dan menganalisis sumber data kepustakaan. Data dalam penelitian ini berupa istilah-istilah bahasa Arab modern dalam bidang politik di dalam kamus Arabic-English Tematic Lexicon karya Daniel Newman. Pengumpulan data dilakukan dengan metode pengamatan atau observasi langsung ${ }^{7}$. Data dalam penelitian ini dianalisis menggunakan metode distribusional teknik top down. Metode distribusional mengunakan alat penentu di dalam unsur bahasa itu sendiri. Dasar penentu di dalam kerja metode kajian distribusional adalah teknik pemilihan data berdasarkan kategori (kriteria) tertentu dari segi kegramatikalan sesuai dengan ciri-ciri alami yang dimiliki oleh 
data penelitian ${ }^{8}$. Adapun metode penyajian hasil analisis data dilakukan secara informal yaitu perumusan dengan kata-kata biasa walaupun dengan terminologi yang teknis sifatnya?

\section{Pembahasan}

\section{Neologi}

Munir Baalbaki di dalam kamus al Mawrid A modern english-Arabic Dictionary menjelaskan mengenai makna neologi yang berasal dari kata neology

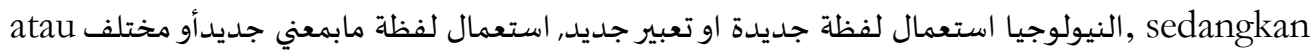

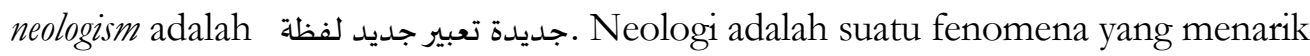
karena kemunculannya menunjukkan kemampuan bahasa untuk menjalani, mempertahankan perubahan, dan kemampuannya untuk mengalihkan gangguan negatif dari bahasa dan budaya yang lain ${ }^{10}$.

Dalam bukunya al Muwallad fi al 'Arabiyyah: Dirasah Fi Numuwni al Lughah al-'Arabiyyah $W a$ Tathawnuriba Ba'da al-Islam, Hilmi Khalil membagi neologi menjadi dua: (1) neologi kata: dalam bentuk kata, (2) neologi komposisi, neologi dalam bentuk susunan atau komposisi kata. Selanjutnya Hilmi Khalil mengemukakan beberapa metode neologi antara lain: (a) neologi dengan cara lebih mengkhususkan makna pada suatu kosa kata, (b) neologi dengan cara menjadikan makna suatu kosa kata lebih umum, (c) neologi karena perbedaan konteks penggunaan suatu kosa kata. Lebih lanjut dalam buku tersebut dijelaskan tentang metode neologi dalam beberapa cara: (a) neologi dengan cara memindahkan makna suatu kosa kata, baik dengan cara memperluas ataupun mempersempit makna, (b) neologi dengan cara derivasi yaitu pembentukan dan penetapan kata baru, baik kata yang memiliki asal atau akarnya di dalam bahasa Arab maupun kata yang berasal dari luar bahasa Arab, (c) neologi dengan cara arabisasi kosa kata asing, (d) neologi dengan cara menerjemahkan kosa kata asing ke dalam bahasa Arab ${ }^{11}$.

Ibrahim Murad dalam bukunya yang berjudul Muqaddimah Li Nazāriyyah al-Mu'jam mengklasifikasikan neologi menjadi lima macam pembentukan dengan 15 kaidah sebagai berikut: (1) Neologi fonetis, mencakup: (a) penggantian fonem, (b) pertukaran posisi fonem, (c) kemiripan fonem, (d) kejelasan pengucapan, (e)

8 T. Fatimah Djajasudarma, Metode Linguistik: Ancangan Metode Penelitian dan Kajian, (Bandung: PT ERESCO, 1993), hlm. 60-61

9 Sudaryanto, Metode dan Aneka Teknik. Analisis Bahasa: Pengantar Penelitian Wahana Kebudayaan Secara Linguistik, (Yogyakarta: Sanata Dharma University Press, 2015), hlm. 241

${ }^{10} \mathrm{~K}$. Ahmad, Neologisms, Nonces and Word Formation. In (Eds.) U. Heid, S. Evert, E. Lehmann \&C. Rohrer. The 9th EURALEX Int. Congress, (8-12 August 2000, Munich.). Vol II. (Munich: Universitat Stuttgart, 2000) hlm. 1

${ }^{11} \mathrm{Hilmi}$ Khalil, Al Muwallad fi Al 'Arabiyyah: Dirasah fì Numuwni Al Lughah Al 'Arabiyyah wa Tathawnurihà Ba'da al Islam, (Beirut: Dār an Nahdlah al 'Arabiyyah, 1985), hlm. 337-434 
sisipan. (2) Neologi morfologis terdiri dari: (a) derivasi, (b) an-nabt, (c) komposisi, (d) leksikal. (3) Neologi semantis, terdiri dari: (a) metafora, (b) translasi. (4) Neologi spontanitas, terdiri dari: (a) spontanitas hikiki, (b) spontanitas imitasi. (5) Neologi pinjaman, terdiri dari: (a) ad-dakhil, (b) arabisasi ${ }^{12}$.

\section{Kajian Morfologis}

Morfologi merupakan bidang linguistik yang mempelajari morfem dan kombinasi-kombinasinya, bagian dari struktur bahasa yang mencakup kata dan bagian-bagian kata, yaitu morfem ${ }^{13}$. Di dalam bahasa Arab morfologi disebut "alNizāmu al-Sarfiy" atau "ilm al-Istyqāq" yaitu perubahan bentuk kata menjadi bermacam-macam bentuk untuk mendapatkan makna yang berbeda-beda ${ }^{14}$. Satuan terkecil dalam morfologi adalah morfem yang mempunyai makna ${ }^{15}$.

Ada tiga hal pokok yang berkaitan dengan morfem. Pertama, morfem mempunyai dan merupakan satu satuan yang formal dan mempunyai rupa fonetik. Kedua, morfem mempunyai makna. Ketiga, morfem mempunyai peranan sintaksis dalam pembentukan satuan-satuan gramatikal yang lebih besar ${ }^{16}$.

Proses morfemis atau proses morfologis merupakan proses pembentukan kata bermorfem jamak baik derivatif maupun inflektif. Proses ini pada umumnya dibedakan atas proses morfemis afiksasi, proses morfemis pergantian atau perubahan, proses morfemis pengulangan, proses morfemis zero, proses morfemis suplesi, dan proses morfemis suprasegmental ${ }^{17}$. Di dalam bahasa Arab derivatif disebut "at tashrif al ishtilahiy", sedangkan inflektif disebut "at tashrif al lughawiy",

\section{Istilah}

Istilah dalam Kamus Besar Bahasa Indonesia berarti kata atau gabungan kata yang dengan cermat mengungkapkan makna konsep, proses, keadaan, atau sifat yang khas dalam bidang tertentu, sebutan nama, kata atau ungkapan khusus. Adapun di dalam bahasa Arab istilah disebut sebagai al musthalah: kullu kalimatin laha dalālatun mu'ayyinatun, muttafaqun 'alaibà baina al 'ulamā' fi 'ilmi mà

${ }^{12}$ Ibrahim Murad, Muqaddimah li Nazāriyyah al Mu’jam, (Tunis: Dār al Gharb al Islamiy, 1997), hlm. 163

${ }^{13}$ Harimurti Kridalaksana, Kamus Linguistik, Jakarta: PT. Gramedia Pustaka Utama, 2011), hlm. 159

14 Sahkholid Nasution, Pengantar Linguistik. Bahasa Arab, (Sidoarjo: CV. Lisan Arab, 2017) hlm. 104

${ }_{15}$ Abdul Chaer, Linguistik Umum, (Jakarta: Rineka Cipta, 2012), hlm. 146

15-16

${ }^{16}$ Joz Daniel Parera, Morfologi Bahasa, (Jakarta: PT Gramedia Pustaka Utama, 1994) hlm.

${ }^{17}$ Ibid, hlm. 18

${ }^{18}$ Sahkholid Nasution, Pengantar Linguistik Bahasa Arab, (Sidoarjo: CV. Lisan Arab, 2017) hlm. 109-111 
(istilah adalah setiap kata yang menunjukkan makna tertentu, disepakati oleh para ilmuan dalam bidang keilmuan tertentu) ${ }^{19}$.

Menurut Kridalaksana istilah merupakan unsur bahasa yang memiliki dua aspek yaitu ungkapan istilah dan makna istilah. Dari segi ungkapan istilah memiliki ciri-ciri yaitu: (1) berupa kata benda, kata kerja atau kata sifat, (2) bangunan istilah sepadan dengan kata tunggal, kata majemuk, kata bersambungan, kata ulang, dan frase. Adapun dari segi makna, istilah memiliki ciri-ciri yaitu: (1) hubungan antara ungkapan dan makna tetap dan tegas (monosemantis), (2) secara gramatikal bebas konteks artinya, makna tidak tergantung dari konteks dalam kalimat, (3) makna dapat dinyatakan dengan definisi atau rumus dalam ilmu yang bersangkutan ${ }^{20}$.

\section{Ilmu Politik}

Politik dalam bahasa Arab disebut 'siyasah' atau yang berarti cerdik dan bijaksana atau politik sebagai suatu cara yang dipakai untuk mewujudkan tujuan ${ }^{21}$.Secara etimologis kata politik berasal dari bahasa Yunani, yaitu polis, yang dapat berarti kota atau negara-kota. Deliar Noer menyebutkan bahwa perkataan 'politik' mengandung berbagai makna yang sangat luas, yakni kekuasaan, kekerasan, wibawa, pengaruh, hubungan dua pihak, perasaan dan keinginan, kepentingan, nilai, keyakinan, dan agama, milik, status dan kelas, tujuan, dan ideologi22.

Berbagai uraian teori-teori diatas inilah yang nantinya akan digunakan oleh peneliti sebagai pisau analisis dalam menjawab permasalahan dalam penelitian yang akan dilakukan tentang pembentukan istilah-istilah bahasa Arab modern dalam bidang politik.

\section{Analisis}

Penelitian ini merupakan penelitian tentang bentuk-bentuk istilah dan kaidah pembentukan istilah politik dalam bahasa Arab yang terdapat di dalam kamus Arabic-English Tematic Lexicon karya Daniel Newman. Kamus ini merupakan kamus berbahasa Arab-Inggris yang terdiri dari sekitar 8000 istilah yang terdiri dari berbagai macam tema. Diantaranya adalah tentang flora dan fauna, makanan dan minum, tubuh manusia, perawatan kesehatan, keluarga, perumahan, pakaian, pendidikan, IT, olahraga, politik, ekonomi dan perdagangan, hukum, media, bahasa, geografi, perjalanan, agama, seni, sains dan

19 https://www.almaany.com/ar/dict/arar/\%D $\% \% 85 \% \mathrm{D} 8 \% \mathrm{~B} 5 \% \mathrm{D} 8 \% \mathrm{~B} 7 \% \mathrm{D} 9 \% 84 \%$ D8\%AD/di akses pada hari senin, 19 Februari 2018 jam 15.09 WIB. hlm. 51

${ }^{20}$ Harimurti Kridalaksana, Fungsi Bahasa dan Sikap Bahasa, (Flores: Nusa Indah, 1982)

${ }^{21}$ Inu Kencana Syafi'ie, Al Quran dan Ilmu Politik, (Jakarta: Rineka Cipta, 1996), hlm. 74

22 Abdul Hakim, M. Thalhah, Politik Bermoral Agama: Tafsir Politik Hamka, (Yogyakarta: UII Press, 2005) hlm. 40-41 
sumber daya alam. Entri dalam kamus leksikon ini diambil dari korpus luas kontemporer Kosakata bahasa Arab standar, berdasarkan sumber-sumber otentik. Selain kata kerja, kata benda dan kata sifat, leksikon termasuk frase dan kolokasi. Kamus ini bertujuan untuk memudahakan para pembelajar bahasa Arab-Inggris dalam memahami bahasa Arab standar yang digunakan dalam keseharian $^{23}$.

Dari berbagai tema yang ada di dalam kamus, peneliti hanya akan berfokus pada bidang politik. Adapun penemuan dari penelitian ini adalah sebagai berikut:

1. Bentuk-Bentuk Istilah Politik di Dalam Bahasa Arab Modern

Bentuk-bentuk istilah politik di dalam bahasa Arab yang ditemukan di dalam kamus Arabic English Tematic Lexicon karya Daniel Newman terdiri dari bentuk kata dan frasa. Di dalam bahasa Arab, kata disebut sebagai "al-kalimab" yaitu lafadz yang menunjukkan makna tunggal. Kata di dalam bahasa Arab dibagi menjadi tiga yaitu: isim, fi'il,dan burf ${ }^{24}$.

Menurut Fuad Ni'mah isim yaitu setiap kata yang menunjukkan manusia, hewan, tumbuh-tumbuhan, benda mati, tempat, waktu, sifat, atau makna yang terbebas dari waktu tertentu. Adapun fi'il adalah setiap kata yang menunjukkan terjadinya sesuatu pada waktu tertentu. Hurf adalah setiap kata yang tidak bemakna jika tidak bergandengan dengan kata lain ${ }^{25}$.

Frase merupakan gabungan dua kata atau lebih yang sifatnya tidak predikatif, gabungan itu dapat rapat, dapat pula renggang ${ }^{26}$. Di dalam bahasa Arab, frase masuk dalam pembahasan tentang murakkab. Al-Ghulāyaini membagi murakkab menjadi enam pembagian yaitu: isnādi, idhäfi, bayāni, 'athfi, mazji, dan 'adadiy. Murakkab isnādi disebut juga dengan jumlah (kalimat) yaitu tersusun atas musnad dan musnad ilaih. Di dalam bahasa Arab dibagi menjadi jumlah ismiyyah dan jumlah fi'liyyah. Al murakekab al idhäfiy yaitu tersusun atas mudhäf dan mudhäf ilaih. Al murakkab al bayāniy yaitu tersusun dari dua kata yang kata kedua sebagai penjelas kata pertama. Al murakekab al bayāniy dibagi menjadi tiga: (a) murakkab washfiy, tersusun dari al-shiffah dan al-maushüf contoh: التلميذ المجتهد, (b) murakkab taukidiy, tersusun atas al muakkid dan al muakkad contoh: القوم كلهم, dan (c) murakkab badaliy tersusun atas al badal dan al mubdal minhu contoh: جاء خليل اخوك. Al murakekab al 'athfiy yaitu sesuatu yang tersusun atas al

${ }^{23}$ Daniel Newman, Arabic-English Tematic Lexicon, (Abingdon: Routledge, 2007) hlm. i

${ }^{24}$ Musthafa Al Ghulāyayniy, Jāmi'u ad Durūs al 'Arabiyyah, (Lebanon: Dar al-Kotob al'Ilmiyah, 2009) hlm. 8

${ }^{25}$ Fuad Ni'mah, Mulakhkhash Qawäid al Lughah al 'Arabiyyah, (Beirut: Dār al Tsaqāah al Islamiyyah, Tt) hlm. 17-18

${ }^{26}$ Harimurti Kridalaksana, Kamus Linguistik, Jakarta: PT. Gramedia Pustaka Utama, 2011) hlm. 66 
ma'thuf dan al ma'thuf alaih dengan perantara burf 'athfiy contoh: الدرس والأجتهاد murakeab al mazjiy yaitu dua kalimat yang tersusun menjadi satu dan menjadi satu kesatuan yang tidak bisa dipisahkan contoh: حضرموت. Al murakkab al 'adadiy yaitu dua bilangan ('adadain) yang diantara keduanya terdapat burf 'athf yang dikirakirakan. Terdiri dari bilangan 11-19 dalam bahasa Arab ${ }^{27}$.

Adapun dari hasil penelitian yang telah dilakukan, bentuk-bentuk istilah politik dalam bahasa Arab disajikan dalam tabel berikut:

a. Bentuk kata

Tabel 1 Istilah Politik dalam Bahasa Arab berbentuk Kata

\begin{tabular}{|c|c|c|c|}
\hline No & Istilah bahasa Arab & Istilah bahasa Inggris & Keterangan \\
\hline 1 & حضر & to attend & Verba \\
\hline 2 & اتّحاد & unity, solodarity & Nomina \\
\hline 3 & اتفاق & Agreement & Nomina \\
\hline 4 & اتفاقية & Convention & Nomina \\
\hline 5 & 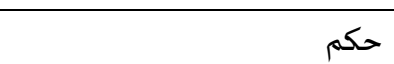 & to govern & Verba \\
\hline 6 & اثّر & to influence & Verba \\
\hline 7 & أجار & to grant asylum & Verba \\
\hline 8 & اجتماع & Meeting & Nomina \\
\hline 9 & اجتمع & to meet & Verba \\
\hline 10 & اجراء, اجراءت & measure, procedure & Nomina \\
\hline
\end{tabular}

Dari hasil observasi yang dilakukan peneliti terhadap kamus Arabic English Tematic Lexicon khusus pada tema politik ditemukan sekitar 489 istilah politik berbentuk kata. Terdapat sekitar 398 istilah berupa nomina dan 91 istilah berupa verba.

Pada tabel diatas dapat diketahui bahwa bentuk istilah politik di dalam bahasa Arab bisa berupa verba maupun nomina. Pada contoh tabel no. 1, 5, 6, 7, dan 9 merupakan bentuk istilah politik berupa verba. Verba bisa berupa verba kata dasar (fiil mujarrad) dan verba berafiks (fi'il mazid). Verba kata dasar seperti pada contoh kata حضر (to attend) dan kata حكم (to govern) yang mengikuti pola "فعل". Adapun bentuk verba berafiks seperti pada contoh kata أجار (to grant asylum) dan اجتمع (to meet) yang mengikuti pola "افعل" dan "افتعل".

Bentuk istilah politik dalam bahasa Arab yang berupa nomina dalam tabel diatas misalnya pada kata اتحاد (unity, solodarity )merupakan nomina beafiks yang terdiri dari prefiks hamzah dan infiks berupa ta dan alif. Kata tersebut mengikuti pola "افتعال"، اتفاق اجتماع (agreement) dan kata 
(meeting). Adapun pada kata اجراء (measure, procedure) merupakn nomina berafiks

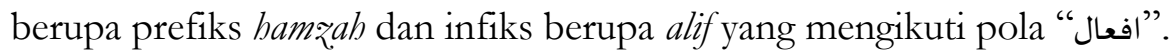

b. Bentuk frasa

Tabel 2 Istilah Politik dalam Bahasa Arab berbentuk Frasa

\begin{tabular}{|c|c|c|c|}
\hline No & Istilah Bahasa Arab & Istilah Bahasa Inggris & Keterangan \\
\hline 1 & اتفق علي & to agree on & frasa verbal \\
\hline 2 & |تفاقية سلام & peace agreement & tarkib wasfi \\
\hline 3 & احصياء السكّان & Census & tarkib idhofi \\
\hline 4 & بالنسبة ل & with respect to & jarr majrur \\
\hline 5 & قائم بالأعمال & change d'affaires & frasa nominal \\
\hline 6 & تمييز عنصري & racial discrimination & tarkib wasfi \\
\hline 7 & تورّط في & involvement in & frasa nominal \\
\hline 8 & توطيد الروابط & strengthening of ties & tarkib idhafi \\
\hline 9 & جار علي & to oppress, tyrannize & frasa verbal \\
\hline 10 & جلسة عامة & plenary meeting & tarkib wasfi \\
\hline
\end{tabular}

Adapun istilah politik berbentuk frasa terdapat sekitar 246 istilah. 31 berupa verba berpreposisi, 107 berupa tarkib wasfi, 89 berupa tarkib idhafi, 6 berupa jumlah fi'liyah, 4 berupa nomina berpreposisi, 3 berupa jarr majrur, 3 berupa jumlah ismiyyah.

Pada contoh tabel no. 1 dan 9 merupakan istilah politik berupa frasa verbal. Frasa verbal merupakan jenis frase endosentris yang intinya berupa verbaa. Pada kata جارعلى (to agree on) dan kata oppress) verba dalam istilah tersebut menjadi inti dari frasa. Adapun pada contoh kata قائم بالأعمال (change d'affaires) dan kata تورّطفي (involvement in) merupakan istilah politik dalam bahasa Arab berupa frasa nominal. Frasa nominal merupakan frasa yang intinya berupa nomina atau pronomina ${ }^{29}$. Adapun pada contoh 2, 6, dan 10 istilah سلام اتفاقية(Peace agreement), تمييز عنصري (racial discrimination), dan جلسة عامة (Plenary meeting) merupakan istilah politik berupa tarkib wasfi yang merupakan frasa terdiri dari shifah berkedudukan sebagai kata yang kedua dan maushuf merupakan kata yang berkedudukan dibagian pertama. Pada contoh no.3 احصاء السكّان (census) dan no. 8 توطيد الروابط (strengthening of ties) merupakan frasa berupa tarkib idhafi yang terdiri dari susunan mudhaf dan mudhaf ilaih. Kata pertama berkedudukan sebaga mudhaf dan kata kedua berkedudukan sebagai mudhaf ilaib.Adapun pada contoh no. 4J

\footnotetext{
${ }^{28}$ Abdul Chaer, Linguistik Umum, (Jakarta: Rineka Cipta, 2012), hlm. 228

${ }^{29} \mathrm{Ibid}, \mathrm{hlm} .228$
} 
بالنسبة (with respect to) merupakan frasa berupa jarr majrur yang terdiri dari hurf jarr dan nomina maupun komponen nomina yang bersifat genetif (majrur).

2. Analisis Pembentukan Istilah Politik dalam Bahasa Arab

Proses pembentukan istilah politik di dalam bahasa Arab ditinjau dari aspek morfologis menggunakan beberapa metode antara lain: a) neologi dengan cara derivasi yaitu pembentukan dan penetapan kata baru, baik kata yang memiliki asal atau akarnya di dalam bahasa Arab maupun kata yang berasal dari luar bahasa Arab terdiri dari: masdar, isim fa'il, isim maf'ul,dan isim makān, b) neologi dengan cara arabisasi kosa kata asing atau penyerapan, dan c) neologi dengan cara menerjemahkan kosa kata asing ke dalam bahasa Arab.

Adapun kaidah pembentukan istilah politik dalam bahasa Arab peneliti sajikan dalam beberapa tabel berikut:

a. Masdar

Masdar merupakan lafadz (kata dalam bahasa Arab) yang menunjukkan kejadian tertentu yang terbebas dari ikatan waktu tertentu, terbentuk dari huruf yang terdapat pada fi'il nya lafadz tersebut ${ }^{30}$. Berikut tabel pembentukan istilah politik dalam bahasa Arab yang berupa masdar:

Tabel 3 Pembentukan Istilah Politik dalam bahasa Arab Berupa Masdar

\begin{tabular}{|c|c|c|c|}
\hline $\mathrm{No}$ & Istilah Bahasa Arab & Istilah Bahasa Inggris & Wazan \\
\hline 1 & اتتحاد & unity, solidarity & افتعال \\
\hline 2 & اتِفاق & Agreement & افتعال \\
\hline 3 & اجتماع & Meeting & افتعال \\
\hline 4 & اجماع & Unanimity & افعال \\
\hline 5 & احتجاج & Protest & افتعال \\
\hline 6 & احتكاك & Controversy & افتعال \\
\hline 7 & احتياط & Precaution & افتعال \\
\hline 8 & احرار & Liberals & افعال \\
\hline 10 & ارتشاء & Venalty & افتعال \\
\hline 11 & استبداد & Despotism & استفعال \\
\hline 12 & استعمار & Colonialism & استفعال \\
\hline 13 & استغلال & Exploitation & استفعال \\
\hline 14 & استفتاء & Referendum & استفعال \\
\hline 15 & استفزاز است & incitement, provocation & استفعال \\
\hline
\end{tabular}

${ }^{30}$ Musthafa Al Ghulāyayniy, Op. Cit., hlm. 123 
Dalam penelitian ini, pembentukan istilah politik dalam bahasa Arab melalui pembentukan masdar mengikuti pola yang telah ada di dalam bahasa Arab. Adapun ditemukan beberapa pola (wazan) yang digunakan dalam pembentukan istilah politik yang berupa masdar antara lain:

فعال، افتعال، افعال، استفعال، انفعال، تفعيل، تفعّل، تفاعل، فعل، فعلة، فعالة، مفاعلة، متفعّل،

مستفعلة.

Pada contoh tabel diatas misalnya pada contoh no. 1-3 yaitu pada istilah اتحاد (unity, solidarityz), اتّفاق (agreement), اجتماع (meeting) pembentukannya mengikuti

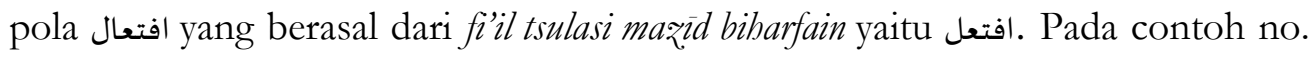
4 dan 8, yaitu pada istilah اجماع احرار (unanimity) dan افعار (liberals) mengikuti pola افعلعال yang berasal dari fi'il tsulasi mazid biharfin yaitu افعل. pada contoh no. 11-15 pada istilah استبداد استعمار (depotism) استغلال (exploitation), استفتاء (referendum),

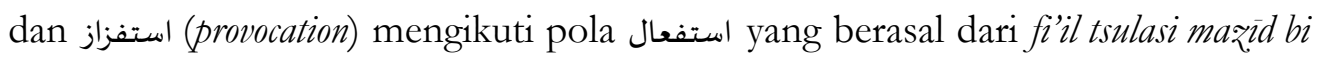
tsalāsati abruf yaitu استفعل

b. Isim fä'il

Isim fäil adalah kata benda yang terbentuk dari kata kerja yang dapat diderivasikan, bersifat mabni ma'lum, bermakna untuk menunjukkan orang yan melakukan suatu pekerjaan pada kejadian tertentu dan tidak tetap ${ }^{31}$. Adapun pembentukan istilah politik dalam bahasa Arab melalui proses derivasi Isim fä'il adalah sebagai berikut:

Tabel 4 Pembentukan Istilah Politik dalam Bahasa Arab Berupa Isim fä̀l

\begin{tabular}{|c|c|c|c|}
\hline $\mathrm{No}$ & Istilah Bahasa Arab & Istilah Bahasa Inggris & Wazan \\
\hline 1 & بارز & Prominent & فاعل \\
\hline 2 & دافع & incentive, motive & 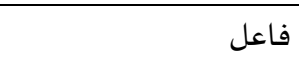 \\
\hline 3 & 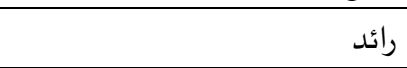 & Pioneer & فاعل \\
\hline 4 & ساحق & Overwhelming & 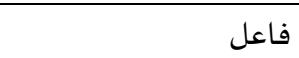 \\
\hline 5 & سفير & Ambassador & 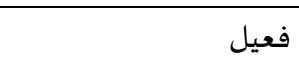 \\
\hline 6 & شامل & Comprebensive & فاعل \\
\hline 7 & شائع & Widespread & فاعل \\
\hline 8 & 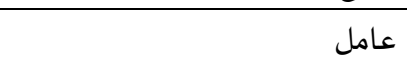 & Factor & 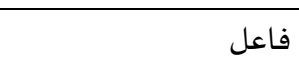 \\
\hline 9 & 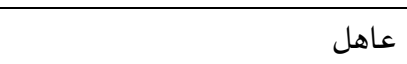 & Monarch & فاعل \\
\hline 10 & عميل ع & agent, collaborator & فعيل \\
\hline 11 & 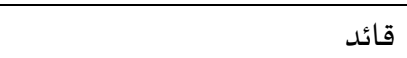 & Leader & فاعل \\
\hline
\end{tabular}

${ }^{31}$ Fakhruddin Qabāwah, Tlmu Sharf, (Lebanon: Maktabah Lebanon Nāsyirūn, 2012) hlm. 149 
114 | Arabiyatuna : Jurnal Bahasa Arab, Vol. 2, No.2, 2018

\begin{tabular}{|l|r|l|r|}
\hline 12 & فاعل & Complete & \\
\hline
\end{tabular}

antara lain:

Pada Isim fa'il wazan yang digunakan dalam pembentukan istilah politik

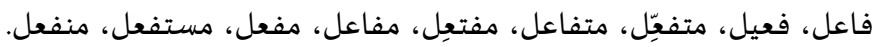

Pada contoh yang terdapat dalam tabel di atas, hanya mengikuti dua pola yaitu pola فاعل dan فعيل. Misalnya pada istilah رائد (pioneer) yang mengikuti pola

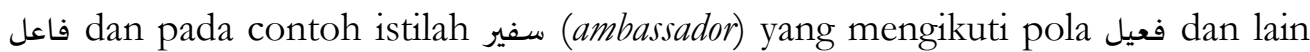
sebagainya.

c. Isim maf'ul

Isim maf'ul adalah kata benda yang diderivasikan dari bentuk masdar fi'il mutasharrif, mabni majhül, untuk menunjukkan makna orang yang dikenai suatu pekerjaan $\mathrm{fa}^{\prime} \mathrm{i}^{2}$. Berikut disajikan tabel pembentukan istilah politik dalam bahasa Arab berupa Isim maf'ul:

Tabel 5 Pembentukan Istilah Politik dalam Bahasa Arab Berupa Isim maf'ul

\begin{tabular}{|c|c|c|c|}
\hline No & Istilah Bahasa Arab & Istilah Bahasa Inggris & Wazan \\
\hline 1 & 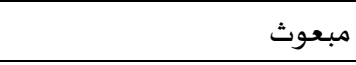 & Envoy & مفعول \\
\hline 2 & مشروع & project, scheme, legitimate, lawful & مفعول \\
\hline 3 & مضميمون & Guaranteed & مفعول \\
\hline 4 & 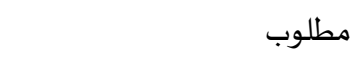 & Demand & مفعول \\
\hline 5 & مندوب & delegate, representative & مفعول \\
\hline 6 & مندوحة & Alternative & مفعولة \\
\hline
\end{tabular}

Pada isim maf'ul wazan yang digunakan dalam pembentukan istilah politik antara lain:

مفعول، مفعولة.

Pada contoh tabel di atas pembentukan istilah politik dalam bahasa Arab yang berupa Isim maf'ul mengikuti pola مفعولة ,مفعول. Misalnya pada contoh no. 1-5 istilah مبعوث (envoy), مشروع (project), مضمون (guaranted), مطعوب (demand), dan (delegate) mengikuti pola مفعول مندوب. Adapun pada contoh no. 6 pada istilah مفعولة alternative) mengikuti pola مفولة. 


\section{d. Isim makān}

Isim makān adalah kata benda yang diderivasikan dari bentuk masdar untuk menunjukkan makna tempat terjadinya pekerjaan ${ }^{33}$. Adapun pembentukan istilah politik dalam bahasa Arab yang berupa isim makān disajikan dalam tabel berikut:

Tabel 6 Pembentukan Istilah Politik dalam Bahasa Arab Berupa Isim

makān
\begin{tabular}{|l|r|l|l|}
\hline No & Istilah Bahasa Arab & Istilah Bahasa Inggris & Wazan \\
\hline 1 & مقعد مفعل & Seat & \\
\hline 2 & مفعل & meeting place & منتدى \\
\hline 3 & موقف & position, stance & \\
\hline
\end{tabular}

Pada isim makän wazan yang digunakan dalam pembentukan istilah politik antara lain: منفعل ,مفعل. Pada tabel di atas dapat diketahui bahwa pembentukan istilah politik dalam bahasa Arab yang berupa isim makān tidak banyak hanya tiga istilah. Pada contoh no. 1 dan 3 pada istilah مقعد (seat) dan مقدف (position, stance) mengikuti pola مفعل dan pada contoh no. 2 pada istilah منتدى (meeting place) mengikuti pola منفعل Sمعل.

e. Penyerapan

Penyerapan di dalam suatu bahasa meliputi dua jenis proses yakni pemasukan (importation) dan proses penggantian (substitution). Proses pemasukan terjadi karena tidak adanya konsep di dalam bahasa sasaran, sehingga kata-kata bahasa sumber diserap bersama konsepnya ${ }^{34}$. Haugen dalam penelitian Hadi mengklasifikasikan hasil penyerapan menjadi loanwords (kata serapan), loanblends(campuran serapan) atau bybrid (hibrida), dan loanshift (geseran serapan). Loanshift meliputi loan translations dan semantic borrowings ${ }^{35}$.

Loanwords yaitu hasil importansi morfemis tanpa substitusi morfemis tetapi dengan atau tanpa substitusi fonemis.Loanblends yaitu gabungan hasil substitusi dan importansi morfemis, namun strukturnya sesuai dengan bentuk kata asing yang diserap. Loanblends disebut juga hibrida (bybrid), yaitu campuran serapan yang strukturnya tidak sesuai dengan bentuk kata asalnya. Loanshift yaitu hasil substitusi morfemis tanpa importasi disebut sebagai a) loan translation (terjemahan serapan, b) semantic loans dan semantic borrowings (serapan semantik).

\footnotetext{
${ }^{33} \mathrm{Ibid}, \mathrm{hlm} .171$

${ }^{34}$ Einar Haugen, The Ecology of Language, (Oxford: Standford University Press, 1971) hlm. 85

35 Syamsul Hadi, Kata-Kata Serapan dari Babasa Arab yang Terdapat dalam Kamus Besar Bahasa Indonesia, (Yogyakarta: Program Studi Linguistik Jurusan Ilmu-Ilmu Humaniora UGM, 2003) hlm. 33-35
} 
Adapun pembetukan istilah politik dalam bahasa Arab disajikan dalam tabel berikut:

Tabel 7 Pembentukan Istilah Politik dalam Bahasa Arab Melalui Penyerapan

\begin{tabular}{|c|c|c|}
\hline No & Istilah Bahasa Arab & Istilah Bahasa Inggris \\
\hline 1 & برلمان & Parlemen \\
\hline 2 & برتوكل & Protocol \\
\hline 3 & بيروقراطية & bureaucracy \\
\hline 4 & دبلوماسي & diplomatic \\
\hline 5 & دبلوماسية & diplomacy \\
\hline 6 & ديموقراطية & democracy \\
\hline 7 & ديموقراطي & democratic \\
\hline 8 & قنصل & Consul \\
\hline 9 & قنصلية & Consulate \\
\hline 10 & اليبرالية & Liberalism \\
\hline 11 & الليبراليون & the liberals \\
\hline
\end{tabular}

Pada pembentukan istilah politik dengan metode penyerapan dilakukan dengan menyerap secara langsung istilah baru tersebut ke dalam bahasa Arab dan menyesuaikan transliterasi yang ada dalam bahasa Arab.

Pada tabel di atas terdapat beberapa contoh istilah politik dalam bahasa Arab yang diserap dari bahasa Inggris. Pada contoh no. 1 kata parlemen diserap menjadi برلمان dengan mengubah huruf "p" menjadi "ب" . Pada contoh no. 2 kata

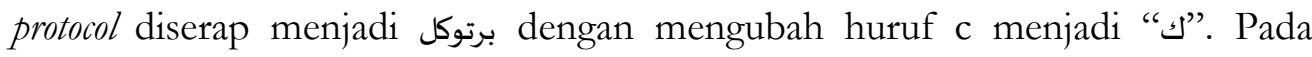
contoh no. 3 bureaucracy diserap menjadi بيروقراطية dengan mengubah huruf c دبلوماسي an c menjadi طada contoh kata diplomatic diserap menjadi dengan mengubah t menjadi س dan lain sebagainya.

f. Terjemahan

Terjemah merupakan pengalihan ide atau gagasan dari suatu bahasa ke bahasa lain ${ }^{36}$. Dalam bukunya "A Textbook of Translation" Newmarkmembagi metode penerjemahan menjadi beberapa metode antara lain: (1) Penerjemahan kata per-kata, yaitu penerjemahan secara langsung kata per-kata dari bahasa sasaran ke dalam bahasa sumber. (2) Penerjemahan Literal yaitu kontstruksi gramatikal bahasa sumber diubah ke bentuk paling dekat dengan bahasa sasaran akan tetapi masih dengan penerjemahan secara leksikal keluar dari konteks. (3)

${ }^{36}$ Ibrahim al Haji Yusuf, Majämi' al 'Arabiyyah fi at Ta'rib, (Kulliyyah al Da'wah al Islamiyyah, 2000), hlm. 37 
Penerjemahan setia, yaitu penerjemahan yang mencoba untuk menghasilkan makna kontekstual secara tepat dengan mempertahankan struktur gramatika dari bahasa sasaran. (4) Penerjemahan semantis, Penerjemahan ini tidak jauh berbeda dengan penerjemahan setia perbedaaanya hanya pada sejauh mana memperhitungkan nilai estetika dari terjemahan. Penerjemahan semantis lebih fleksibel dibandingkan dengan penerjemahan setia. (5) Adaptasi, merupakan metode penerjemahan paling bebas, umumnya digunakan pada teks komedi dan puisi. Budaya bahsa sumber diubah ke dalam bahasa sasaran. (6) Penerjemahan bebas, merupakan penerjemahan tanpa cara, konten tanpa bentuk aslinya, biasanya parafrase lebih panjang daripada aslinya, yang disebut 'terjemahan intralingual dan sering bertele-tele. (7) Penerjemahan idiomotik, penerjemahan ini mereproduksi 'pesan' dari aslinya tetapi cenderung mendistorsi nuansa makna dengan lebih memilih bahasa sehari-hari dan idiom yang tidak ada di dalam bahasa asli. (8) Penerjemahan komunikatif, merupakan metode penerjemahan yang berusaha untuk membuat makna kontekstual yang tepat dari aslinya yang dapat membuat konten dan bahasa dapat diterima dan dipahami oleh pembaca ${ }^{37}$.

Adapun pembentukan istilah politik dalam bahasa Arab melalui penerjemahan disajikan dalam tabel berikut:

Tabel 8 Pembentukan Istilah Politik dalam Bahasa Arab Melalui

Penerjemahan

\begin{tabular}{|c|r|l|}
\hline No & Istilah bahasa Arab & Istilah bahasa Inggris \\
\hline 1 & احرارد & Liberals \\
\hline 2 & $ث$ ثلاثيّ & Tripartite \\
\hline 3 & ثنائيّ & Bilateral \\
\hline 4 & حرّ & liberal \\
\hline
\end{tabular}

Pada proses pembentukan istilah politik melalui metode penerjemahan dilakukan dengan cara menerjemahkan istilah asing ke dalam bahasa Arab sehingga memiliki makna dan pemahaman yang sama. Pada contoh no. 1 istilah liberals diterjemahkan ke dalam bahasa Arab menjadi احرار , pada contoh no. 3 istilah tripartite diterjemahkan ke dalam bahasa Arab menjadi ثُحرار dan pada contoh no. 3 istilah bilateral diterjemahkan ke dalam bahasa Arab menjadi ثنائيّ

\section{Kesimpulan}

Hasil dari penelitian ini menunjukkan bahwa istilah politik di dalam kamus Arabic English Tematic Lexicon terdapat tiga bentuk yaitu berupa kata tunggal, frasa, dan kalimat (jumlah). Dari hasil penelitian ditemukan sekitar 489 istilah politik berbentuk kata, 398 istilah berupa nomina dan 91 istilah berupa

${ }^{37}$ Peter Newmark, A Textbook of Translation, (Tokyo: Shanghai Foreign Language Education Press, 1988), 40-41 
verba. Adapun istilah politik berbentuk frasa terdapat sekitar 246 istilah. 31 berupa verba berpreposisi, 107 berupa tarkib wasfi, 89 berupa tarkib idhafi, 6 berupa jumlah fi'liyah, 5 berupa nomina berpreposisi, 3 berupa jarr majrur, 3 berupa jumlah ismiyyah. Adapun dalam kaidah pembentukan istilah politik dalam bahasa Arab terdapat beberapa metode antara lain: 1) neologi dengan cara derivasi terdiri dari: masdar, isim fa'il, isim maf'ül,dan isim makän, 2) penyerapan, 3) penerjemahan, dan 4) hibrida. 


\section{Bibliografi}

Ahmad, K. Neologisms, Nonces and Word Formation. In (Eds.) U. Heid, S. Evert, E. Lehmann \&C. Rohrer. The 9th EURALEX Int. Congress. (8-12 August 2000, Munich.). Vol II. Munich: Universitat Stuttgart. 2000

Al Ghulāyayniy, Musthafa, Jämi'u ad-Durūs al 'Arabiyyah, Lebanon: Dar al-Kotob al-'Ilmiyah. 2009

Baalbaki, Munir, Al-Mawrid A Modern English-Arabic Dictionary, Beirut: Dār Al Ilm Lil Malayeen, 1974

Bakalla, M.H., Arabic Culture Through its Language and Literature, London: Kegan Paul International, 1984

Chaer, Abdul, Linguistike Umum, Jakarta: Rineka Cipta, 2012

Departemen Pendidikan Nasional, Kamus Besar Bahasa Indonesia, Jakarta: PT. Gramedia Pustaka Utama, 2014

Djajasudarma, T. Fatimah, Metode Linguistik: Ancangan Metode Penelitian dan Kajian, Bandung: PT ERESCO, 1993

Fachrudin, Aziz Anwar, Pengantar Sejarah dan Mazhab Linguistik Arab, Sidoarjo: CV. Lisan Arabi, 2017

Hadi, Syamsul, Kata-Kata Serapan dari Bahasa Arab yang Terdapat dalam Kamus Besar Bahasa Indonesia, Yogyakarta: Program Studi Linguistik Jurusan IlmuIlmu Humaniora UGM. 2003

Hakim, Abdul, M. Thalhah, Politik Bermoral Agama: Tafsir Politik Hamka, Yogyakarta: UII Press, 2005

Haugen, Einar, The Ecology of Language, Oxford: Standford University Press, 1971

Khalil, Hilmi, Al-Munallad fì Al 'Arabiyyah: Dirasah fi Numumwi Al Lughah Al 'Arabiyyah wa Tathawmurihā Ba'da al Islam, Beirut: Dār an Nahdlah al'Arabiyyah. 1985

Kridalaksana, Harimurti, Fungsi Bahasa dan Sikap Bahasa, Flores: Nusa Indah, 1982 , Kamus Linguistik, Jakarta: PT. Gramedia Pustaka Utama, 2011

Murad, Ibrahim, Muqaddimah Li Nazāriyyah al-Mu'jam, Tunis: Dār al Gharb al Islamiy, 1997

Nasution, Sahkholid, Pengantar Linguistik Bahasa Arab, Sidoarjo: CV. Lisan Arab, 2017

Nazir, Moh., Metode Penelitian, Jakarta: Ghalia Indonesia, 1988

Newman, Danil, Arabic-English Tematic Lexicon, Abingdon: Routledge, 2007 
Newmark, Peter, A Textbook of Translation, Tokyo: Shanghai Foreign Language Education Press, 1988

Ni'mah, Fuad, Mulakhkhash Qawäid al Lughah al 'Arabiyyah, Beirut: Dār al Tsaqāfah al Islamiyyah, $\mathrm{Tt}$

Parera, Jos Daniel, Sintaksis, Jakarta: PT Gramedia Pustaka Utama. 1993. , Morfologi Bahasa, Jakarta: PT Gramedia Pustaka Utama, 1994

Qabāwah, Fakhruddin, Tlmu Sharf, Lebanon: Maktabah Lebanon Nāsyirūn, 2012

Ramlan, M., Ilmu Babasa Indonesia: Sintaksis, Yogyakarta: Karyono, 1987

Shoelhi, Mohammad, Komunikasi Lintas Budaya dalam Dinamika Komunikasi Internasional, Bandung: Simbiosa Rekatama Media, 2015

Sudaryanto, Metode dan Aneka Teknik. Analisis Babasa: Pengantar Penelitian Wabana Kebudayaan Secara Linguistik, Yogyakarta: Sanata Dharma University Press, 2015

Syafi'ie, Inu kencana, Al Quran dan Ilmu Politik, Jakarta: Rineka Cipta, 1996

Waridah, Ernawati, EYD: Ejaan yang Disempurnakan dan Seputar KebahasaIndonesiaan, Bandung: Ruang Kata, 2012

Yusuf, Ibrahim al-Haji, Majämi' al 'Arabiyyah Fi at-Ta'rib, Kulliyyah al Da'wah al Islamiyyah, 2000

https://www.almaany.com/ar/dict/arar/\%D9\%85\%D8\%B5\%D8\%B7\%D $\%$ $84 \% \mathrm{D} 8 \% \mathrm{AD} /$ 